\title{
INVESTIGATION OF THE LUMINESCENCE SPECTRUM OF $\mathrm{UO}_{2} \mathrm{MoO}_{4}$
}

\author{
W.M.A. SMIT and G. BLASSE \\ Physical Laboratory, University of Utrecht, P.O. Box 80.000, 3508 TA Utrecht, The Nether- \\ lands
}

Received 2 March 1984

\begin{abstract}
By time-resolved spectroscopy the intrinsic emission spectrum of $\mathrm{UO}_{2} \mathrm{MoO}_{4}$ at $4.2 \mathrm{~K}$ is obtained. The main progressions in the vibronic structure are identified as couplings with the $\mathrm{A}_{\mathrm{g}}$ correlation field components of the symmetric and asymmetric $\mathrm{UO}_{2}$ stretching modes. The intrinsic zero-phonon line in the emission and excitation spectrum is shown to be split both by the crystal field and correlation field. The steady-state emission spectrum at $4.2 \mathrm{~K}$ is dominated by emission from traps. The vibronic structure of the trap emission reveals that all traps are distorted uranyl groups.
\end{abstract}

\section{Introduction}

In addition to earlier work carried out in this laboratory on the luminescence of uranates and uranyl compounds [1-6] we have studied the luminescence behaviour of $\mathrm{UO}_{2} \mathrm{MoO}_{4}$. In most cases both the excitation and emission spectra of uranium compounds show an intrinsic zero-phonon line of varying intensity and a number of vibronic lines. At low temperatures the emission spectrum is usually dominated by a number of zero-phonon lines pertaining to distorted uranium sites (traps). The trap origins are also accompanied by vibronic satellites.

Additional complexity may arise in cases of low crystal and/or site symmetry or in cases that the primitive unit cell contains more than one molecule.

Previously, we studied $\mathrm{Cs}_{2} \mathrm{UO}_{2} \mathrm{Cl}_{4}$ [6] which crystallizes in the space group $\mathrm{C} 2 / \mathrm{m}-\mathrm{C}_{2 \mathrm{~h}}^{3}$ [7]. The face-centered monoclinic cell contains two molecules but the primitive rhombohedral unit cell contains a single molecule. The uranium ion is on a site with $\mathrm{C}_{2 \mathrm{~h}}$ symmetry. We also studied $\mathrm{Cs}_{2} \mathrm{UO}_{2} \mathrm{Br}_{4}$ [5] with space group $\mathrm{P} 2{ }_{1} / \mathrm{c}-\mathrm{C}_{2 h}^{5}[8,9]$. The monoclinic unit cell contains two molecules and uranium is on sites with $\mathrm{C}_{i}$ symmetry. Here we present an investigation of the emission and excitation spectrum of $\mathrm{UO}_{2} \mathrm{MoO}_{4}$. The crystal structure of this compound is known $[10,11]$. The space group is $\mathrm{P} 2 / / \mathrm{c}-\mathrm{C}_{2 \mathrm{~h}}^{5}$ with four molecules in the monoclinic unit cell. The uranium ions occupy sites with $C_{1}$ symmetry, revealing that the uranyl groups have lost their usual $D_{\infty \mathrm{h}}$ symme-

0022-2313/84/\$03.00 1 Elsevier Science Publishers B.V.

(North-Holland Physics Publishing Division) 
try. It is also of interest to see whether there is any interaction between the uranyl and molybdate groups or not. In this paper we present the spectral data. In a next paper decay measurements will be discussed in connection with energy migration.

\section{Experimental}

Powders of $\mathrm{UO}_{2} \mathrm{MoO}_{4}$ were obtained by heating stoichiometric quantities of $\mathrm{UO}_{2}\left(\mathrm{NO}_{3}\right)_{2} \cdot 6 \mathrm{H}_{2} \mathrm{O}$ and $\mathrm{MoO}_{3}$ up to $100-120{ }^{\circ} \mathrm{C}$ until all crystal water was removed, followed by firing the grinded mixture up to $550{ }^{\circ} \mathrm{C}$ under an oxygen atmosphere during 16 hours. Then the powder was grinded again and a second firing period of the same length and at the same temperature followed. The composition of the final bright-yellow powder was checked by X-ray diffraction. Infrared spectra were measured on a Perkin-Elmer infrared spectrofotometer, model 580B, by using the CsI pellet technique.

Raman spectra were obtained by exciting the powder with the 488 and 515 $\mathrm{nm}$ lines of an Argon ion laser (Spectraphysics model 165), being the light source of a Spectraphysics Ramanspectrometer, model 700.

Excitation and emission spectra were obtained by exciting the powder with a tunable dye laser (Molectron DL200), pumped with a nitrogen laser (Molectron UV14). Peak power of the dye laser pulses is $55 \mathrm{~kW}$, the pulse length being about $10 \mathrm{~ns}$ at a repetition frequency of $30 \mathrm{~Hz}$. The bandwidth of the dye laser is about $0.3 \mathrm{~cm}^{-1}$. The following dyes were used: coumarin 500 , 485, 481 and 460 (obtained from Exciton and/or Radiant Dyes Chemie). Emission spectra were also obtained with a continuous light source, viz., a 450 W high-pressure Xenon lamp (XBO 450W/4). In all cases the emission was resolved with a Spex 1704 one-meter monochromator and detected with a photomultiplier ( $\mathrm{RCA} \mathrm{C} 31034$, cooled to $-30^{\circ} \mathrm{C}$ ). For time averaging and amplification of the photomultiplier signal a Philips PM 2436 microvoltmeter (in the current metermode) was used. The time dependent measurements were carried out with a PAR model 162 boxcar averager together with a PAR model 165 gated integrator. The temperature dependence of the emission spectrum was investigated by mounting the powdered samples in a bath cryostat (Thor cryogenics, type S-100). The temperature of the samples could be varied from $4.2 \mathrm{~K}$ to room temperature by use of a temperature controller (Thor cryogenics, model $3020 \mathrm{II}$ ). Temperatures from $4.2 \mathrm{~K}$ down to $1.2 \mathrm{~K}$ were achieved by pumping of the helium.

\section{Results and discussion}

(A) Intrinsic emission spectrum

At $4.2 \mathrm{~K} \mathrm{UO}_{2} \mathrm{MoO}_{4}$ shows a bright-green luminescence with a high quan- 
tum yield (80-90\%) which decreases gradually at increasing temperature. At $100 \mathrm{~K}$ the quantum efficiency is about $15 \%$, at room temperature of the order of $1 \%$. The intrinsic emission spectrum can be obtained by time resolved spectroscopy (TRS). By taking the emission spectrum at $50 \mathrm{~ns}$ after the pulse the intrinsic emission spectrum is observed (see fig. 1). A time interval of $50 \mathrm{~ns}$ appears to be short enough to avoid the observation of trap emission. Apart from a rather weak intrinsic zero-phonon line a number of vibronic lines is observed. The main vibronic features are easily interpreted as couplings with the internal stretching modes of the uranyl group. The frequencies of the

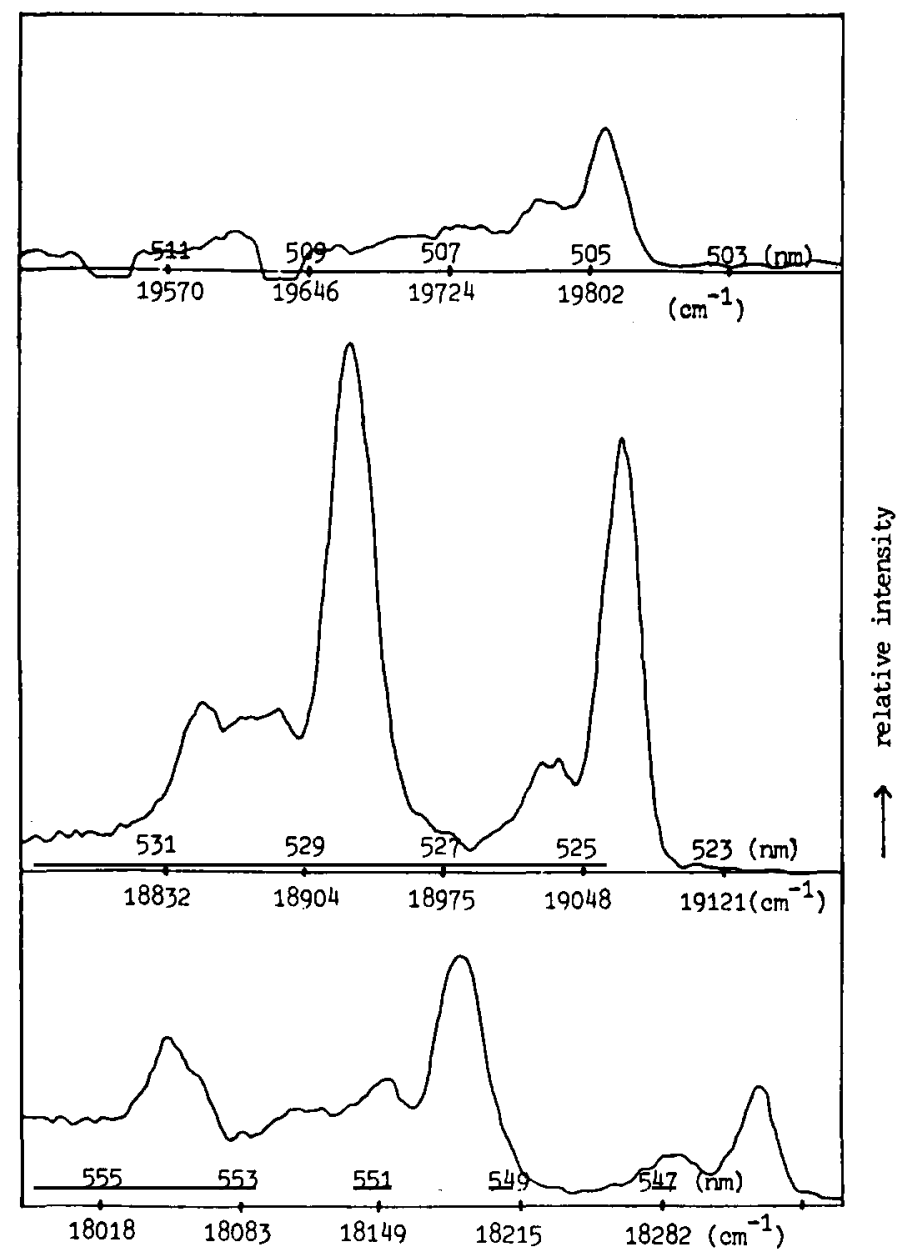

Fig. 1. Time-resolved intrinsic emission spectrum of $\mathrm{UO}_{2} \mathrm{MoO}_{4}$ at $4.2 \mathrm{~K}$ (taken at $50 \mathrm{~ns}$ after the pulse). $\lambda_{\text {exc }}$ is $463.14 \mathrm{~nm}$. The same intensity scale is used for all parts of the spectrum. 
observed maxima of the zero-phonon line and the vibronic lines are given in table 1. Also the assignment of the vibronic progressions is given in the same table. The fundamental vibrational frequencies pertaining to the electronic ground state (indicated as $\nu_{01}$ in table 1) which show up in the emission spectrum are readily recognized from the Raman data of table 2 . This table contains the infrared and Raman frequencies of $\mathrm{UO}_{2} \mathrm{MoO}_{4}$ and for comparison also the corresponding data of the isostructural compound $\mathrm{UO}_{2} \mathrm{WO}_{4}$ [12]. Undoubtedly, the strong Raman line at $745.1 \mathrm{~cm}^{-1}$ must be assigned to the symmetric uranyl stretching mode, whereas the strong IR band at $884.2 \mathrm{~cm}^{-1}$ belongs to the asymmetric uranyl stretching mode. The corresponding features for $\mathrm{UO}_{2} \mathrm{WO}_{4}$ are found at 748 and $883 \mathrm{~cm}^{-1}$, respectively. Inspection of table 2 shows that the strong $\mathrm{UO}_{2}$ bands in the infrared spectra have weaker counterparts in the Raman spectra and vice versa $\left(\mathrm{UO}_{2} \mathrm{MoO}_{4}: 884.2\right.$ vs $884.5,745.1$ vs $746.9, \mathrm{UO}_{2} \mathrm{WO}_{4}: 883$ vs 880,748 vs 747 ). This is noteworthy, since in view of the crystal symmetry $\left(\mathrm{C}_{2 \mathrm{~h}}\right)$ gerade modes are expected in the Raman spectra, whereas the ungerade modes should be active in the infrared. The only satisfactory explanation results from the fact that the crystal structure of these compounds consists of primitive unit cells containing four molecular units. The isolated $\mathrm{UO}_{2}^{2+}$ group has $\mathrm{D}_{\infty \mathrm{h}}$ symmetry so that the $\mathrm{UO}_{2}$ stretching modes belong to symmetry species $\Sigma_{\mathrm{g}}^{+}$(symmetric stretching) and $\Sigma_{\mathrm{g}}^{-}$(asymmetric stretching). However, taking into account that in the unit cell of $\mathrm{UO}_{2} \mathrm{MoO}_{4}$ the four $\mathrm{UO}_{2}$ groups occupy sites with $\mathrm{C}_{1}$ symmetry, both the $\Sigma_{\mathrm{g}}^{+}$and $\Sigma_{\mathrm{g}}^{-}$ representations go over into A-type representations. Under $\mathrm{C}_{2 \mathrm{~h}}$ cell symmetry the reducible representation $4 \mathrm{~A}$ yields four correlated modes belonging to the species $A_{g}+B_{g}+A_{u}+B_{u}$. If we neglect mixing of the symmetric and asym-

Table 1

Observed line positions ${ }^{(a)}$ in the intrinsic emission spectrum of $\mathrm{UO}_{2} \mathrm{MoO}_{4}$ and assignment ${ }^{\left({ }^{(b)}\right.}$ of the vibronic progressions

\begin{tabular}{lllllll}
\hline $\mathrm{i}$ & $\nu_{01}(\mathrm{ss})$ & $\mathrm{v} 1$ & $\nu_{12}$ (ss) & $\mathrm{v} 3$ & $\nu_{23}(\mathrm{ss})$ & $\mathrm{v6}$ \\
19820 & -745 & 19075 & -743 & 18332 & $(-742)^{(\mathrm{c})}$ & $(17590)^{(\mathrm{c})}$ \\
& $\nu_{01}$ (as) & $\mathrm{v} 2$ & $\nu_{01}(\mathrm{ss})$ & $\mathrm{v} 4$ & $\nu_{12}(\mathrm{ss})$ & $\mathrm{v} 7$ \\
& -885 & 18935 & -745 & 18190 & -743 & 17447 \\
& & $\nu_{12}$ (as) & $\mathrm{v} 5$ & $\nu_{01}(\mathrm{ss})$ & $\mathrm{v} 8$ \\
& & -877 & 18058 & -745 & 17313 \\
& & & & $\nu_{23}$ (as) & $\mathrm{v} 9$ \\
& & & & -869 & 17189
\end{tabular}

(a) Observed at $4.2 \mathrm{~K}$. Line positions given in $\mathrm{cm}^{-1}$.

(b) $\mathrm{i}=$ intrinsic electronic origin; $v j(j=1-9)$ : vibronic emission lines; $v_{i j}$ : energy difference between vibrational levels $i$ and $j$ of the electronic ground state; ss: symmetric $\mathrm{UO}_{2}$ stretching; as: asymmetric $\mathrm{UO}_{2}$ stretching

(c) Less accurate frequencies. 
Table 2

Infrared and Raman frequencies (in $\mathrm{cm}^{-1}$ ) of solid $\mathrm{UO}_{2} \mathrm{MoO}_{4}$ and $\mathrm{UO}_{2} \mathrm{WO}_{4}$

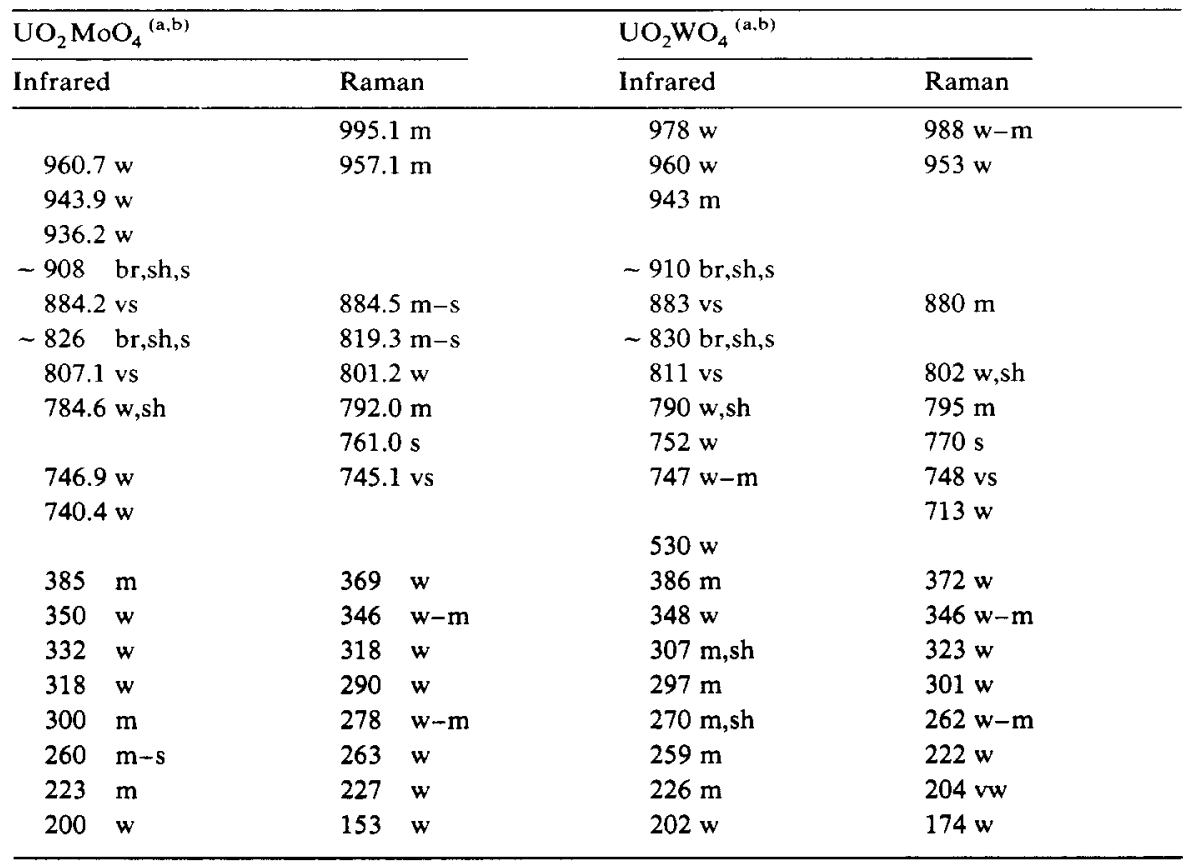

(a) For $\mathrm{UO}_{2} \mathrm{MoO}_{4}$ accuracy in the region $1000-500 \mathrm{~cm}^{-1}: \pm 0.3 \mathrm{~cm}^{-1}$. Accuracy of all other frequencies: IR $\pm 2 \mathrm{~cm}^{-1} ; \operatorname{Raman} \pm 3 \mathrm{~cm}^{-1}$. Relative intensities are roughly indicated as follows: $w=$ weak, $m=$ medium, $(v) s=$ (very) strong, $b r=$ broad, $s h=$ shoulder.

(b) Infrared frequencies of $\mathrm{UO}_{2} \mathrm{MoO}_{4}$ in the region $1000-500 \mathrm{~cm}^{-1}$ were measured at liquid nitrogen temperature. All other frequencies measured at room temperature.

metric modes, the correlated symmetric $\mathrm{UO}_{2}$ stretching modes lead to two absorption bands in the infrared, viz., the $A_{u}$ and $B_{u}$ species, and two Raman lines, viz., the $A_{g}$ and $B_{g}$ species. Exactly the same arguments apply to the correlation field components of the asymmetric stretching mode. The observed $\mathrm{UO}_{2}$ stretching frequencies for $\mathrm{UO}_{2} \mathrm{MoO}_{4}$ are therefore assigned as follows: $\mathrm{UO}_{2}$ symmetric stretching, $746.9 \mathrm{~cm}^{-1}\left(\mathrm{~A}_{\mathrm{u}}+\mathrm{B}_{\mathrm{u}}\right), 745.1 \mathrm{~cm}^{-1}\left(\mathrm{~A}_{\mathrm{g}}+\mathrm{B}_{\mathrm{g}}\right), \mathrm{UO}_{2}$ asymmetric stretching, $884.2 \mathrm{~cm}^{-1}\left(\mathrm{~A}_{\mathrm{u}}+\mathrm{B}_{\mathrm{u}}\right), 884.5 \mathrm{~cm}^{-1}\left(\mathrm{~A}_{\mathrm{g}}+\mathrm{B}_{\mathrm{g}}\right)$. A similar assignment holds for $\mathrm{UO}_{2} \mathrm{WO}_{4}$. The small frequency differences between the corresponding gerade and ungerade modes shows that the correlation field splitting is rather small. Very likely, the splitting is too small to result in separate maxima for the $\mathrm{A}_{\mathrm{g}}$ and $\mathrm{B}_{\mathrm{g}}$ components in the Raman spectrum and the $A_{u}$ and $B_{u}$ components in the infrared spectrum.

In view of the above results it is worthwhile to re-examine the results obtained by Wong et al. [13], Flint and Tanner [14], and Krol and Roos [5] for 
$\mathrm{Cs}_{2} \mathrm{UO}_{2} \mathrm{Br}_{4}$. As mentioned above this molecule crystallizes in space group $\mathrm{P} 2_{1} / \mathrm{c}-\mathrm{C}_{2 \mathrm{~h}}^{5}[8,9]$ with $Z=2$ and uranium at sites of $\mathrm{C}_{i}$ symmetry. This may lead to correlation field splitting of the $\mathrm{UO}_{2}$ stretching modes, giving $\mathrm{A}_{\mathrm{u}}+\mathrm{B}_{\mathrm{u}}$ components for the asymmetric stretching and $\mathrm{A}_{\mathrm{g}}+\mathrm{B}_{\mathrm{g}}$ components for the symmetric stretching. Since the shortest $\mathrm{U}$-U distance in $\mathrm{Cs}_{2} \mathrm{UO}_{2} \mathrm{Br}_{4}$ is $5.85 \AA$ as compared to $4.195 \AA$ in $\mathrm{UO}_{2} \mathrm{MoO}_{4}$ the actual correlation field splitting in $\mathrm{Cs}_{2} \mathrm{UO}_{2} \mathrm{Br}_{4}$ is certainly not larger than in $\mathrm{UO}_{2} \mathrm{MoO}_{4}$. It is very likely, therefore, that the splitting is not observed in the infrared and Raman spectra. This is confirmed by the Raman data of Wong et al. [13], showing an intensive single line at $836 \mathrm{~cm}^{-1}$. Also Flint and Tanner [14] observed a single Raman line at $834 \mathrm{~cm}^{-1}$ at $120 \mathrm{~K}$. However, the infrared data of Flint and Tanner, measured at $85 \mathrm{~K}$, show two strong bands at 925 and $917 \mathrm{~cm}^{-1}$, which are interpreted by the authors as the correlation field components of the asymmetric $\mathrm{UO}_{2}$ stretching mode. There is also the possibility of a Fermi resonance between $\nu_{2}\left(\mathrm{UO}_{2}\right.$ asymmetric stretching) and $\nu_{1}+\nu_{9}$ (combination of $\nu_{1}, \mathrm{UO}_{2}$ symmetric stretching and $\nu_{9}, \mathrm{UBr}_{4}$ out-of-plane bending), also mentioned by Flint and Tanner. In view of the present results which indicate that the correlation field splitting for the asymmetric stretching modes is smaller than for the symmetric stretching modes, the Fermi resonance interpretation seems preferable. Furthermore, it is of interest to observe that both Wong et al. [13] and Krol and Roos [5] report the splitting of a vibronic line in the emission spectrum of $\mathrm{Cs}_{2} \mathrm{UO}_{2} \mathrm{Br}_{4}$ at $4.2 \mathrm{~K}$ which is interpreted as $\mathrm{i}+\nu_{1}$, and also a similar splitting of a vibronic trap line, interpreted as trap $+\nu_{1}$. The $\nu_{1}$ values obtained from $\mathrm{i}+\nu_{1}$ are 835 and $837 \mathrm{~cm}^{-1}$, the average being in excellent agreement with the value of $836 \mathrm{~cm}^{-1}$ obtained from the Raman spectrum. Almost similar values are obtained from the trap line. The obvious interpretation, which is not given in the original papers $[5,13]$ seems to be that 835 and $837 \mathrm{~cm}^{-1}$ are the frequency values for the correlation field components of the $\mathrm{UO}_{2}$ symmetric stretching mode. This small splitting is not resolved in the Raman spectrum at $298 \mathrm{~K}$ [13] and at $120 \mathrm{~K}$ [14], but shows up in the emission spectrum at $4.2 \mathrm{~K}$. The splitting is not reported by Flint and Tanner who measured the emission spectrum at $20 \mathrm{~K}$ at which temperature the trap is thermally depopulated and the splitting of the $i+\nu_{1}$ line is more difficult to observe, especially under lower resolution conditions [15].

The remaining frequencies in the infrared and Raman spectra of $\mathrm{UO}_{2} \mathrm{MoO}_{4}$ in the $1000-700 \mathrm{~cm}^{-1}$ region must be assigned to the stretching modes of the $\mathrm{MoO}_{4}$ group. No attempt is made for a detailed assignment, at the one hand because of the fact that these frequencies are not observed in the emission spectrum of $\mathrm{UO}_{2} \mathrm{MoO}_{4}$, at the other hand because of the complexity of this region. This is partly due to the large number of $\mathrm{MoO}_{4}$ stretching modes, taking into account correlation field splitting (IR: $4 \mathrm{~A}_{\mathrm{u}}+4 \mathrm{~B}_{\mathrm{u}}$, Raman: $4 \mathrm{~A}_{\mathrm{g}}+$ $4 \mathrm{~B}_{\mathrm{g}}$ ) but also overtones and / or combinations from the bending region (400-200 $\mathrm{cm}^{-1}$ ) may interfere. Moreover, in view of the low symmetry, some mixing of 
$\mathrm{UO}_{2}$ and $\mathrm{MoO}_{4}$ modes cannot be excluded. For a complete assignment one needs single crystal spectra and isotopic substitutions. Similar arguments apply to the bending region for which no assignment is given either. Vibronic coupling with bending modes is not observed. If present, the resulting vibronic lines must be very weak.

Returning now to table 1 , the $745 \mathrm{~cm}^{-1}$ difference, which is found three times, viz., $\mathrm{i}-\mathrm{v} 1$, v2-v4, v5-v8, is assigned to the $\mathrm{A}_{\mathrm{g}}$ and $\mathrm{B}_{\mathrm{g}}$ correlation field components of the symmetric $\mathrm{UO}_{2}$ stretching mode. Similarly, the $885 \mathrm{~cm}^{-1}$ difference, also found three times, viz., i-v2, v1-v4, v3-v7, may be identified as the $A_{g}$ and $B_{g}$ components of the asymmetric stretching mode, although, in view of the small frequency difference between the correlation field components, the $A_{u}$ and $B_{u}$ components cannot be excluded at this stage. The remaining differences in table 1 will be discussed later. It is useful to notice that, if the observed progressions are in the $\mathrm{A}_{\mathrm{g}}$ components of the $\mathrm{UO}_{2}$ stretching modes this would indicate that the corresponding pure electronic transition is electric-dipole allowed.

In order to get insight in the symmetry of the electronic energy levels involved we adopt the successful model developed by Denning et al. [16,17]. By using the $7 \mathrm{~s}, 6 \mathrm{~d}$ and $5 \mathrm{f}$ uranium atomic orbitals and the $2 \mathrm{p}$ oxygen atomic orbitals as a basis, the molecular orbitals for $\mathrm{UO}_{2}^{2+}$ under $\mathrm{D}_{\infty \mathrm{h}}$ symmetry are $\sigma_{\mathrm{g}}^{+}, \sigma_{\mathrm{u}}^{+}, \pi_{\mathrm{u}}, \pi_{\mathrm{g}}, \delta_{\mathrm{u}}, \phi_{\mathrm{u}}$, and $\delta_{\mathrm{g}}$, leading to the electronic ground state ${ }^{1} \Sigma_{\mathrm{g}}^{+}$: $\left(\sigma_{\mathrm{g}}^{+}\right)^{2}\left(\pi_{\mathrm{g}}\right)^{4}\left(\sigma_{\mathrm{u}}^{+}\right)^{2}\left(\pi_{\mathrm{u}}\right)^{4}$. The excited electronic states are derived from the electronic configurations $\sigma_{\mathrm{u}} \delta_{\mathrm{u}}, \sigma_{\mathrm{u}} \phi_{\mathrm{u}}, \pi_{\mathrm{u}}^{3} \delta_{\mathrm{u}}$, and $\pi_{\mathrm{u}}^{3} \delta_{\mathrm{u}}$. These excited states are all gerade, thus all electric dipole transitions from the ${ }^{1} \Sigma_{\mathrm{g}}^{+}$ground state to the excited states are Laporte forbidden. As shown by Denning et al. [16,17], the lowest excited state has $\Pi_{\mathrm{g}}$ symmetry under $\mathrm{D}_{\infty \mathrm{h}}$ point symmetry. In solid $\mathrm{UO}_{2} \mathrm{MoO}_{4}$, however, the cylindrical symmetry of the $\mathrm{UO}_{2}^{2+}$ group is removed. The crystal structure reveals that the uranium ions are coordinated by seven oxygen ions according to a distorted pentagonal bipyramid [10]. The five equatorial oxygen atoms belong to four different $\mathrm{MoO}_{4}$ tetrahedra and one neighbouring $\mathrm{UO}_{2}^{2+}$ group, as shown in fig. 2 . The equatorial $\mathrm{U}-\mathrm{O}$ distances range from 2.30 to $2.51 \AA$, while the $\mathrm{U}-\mathrm{O}$ distances of the $\mathrm{UO}_{2}$ group are 1.81 and $1.76 \AA$. Moreover, the equatorial oxygen positions are significantly shifted from the equatorial plane, the shifts ranging from -0.31 to $+0.35 \AA$ with respect to the plane. Hence, the symmetry of the $\mathrm{UO}_{2}$ group is $\mathrm{C}_{1}$ and only very roughly it may be considered as $\mathrm{D}_{5 \mathrm{~h}}$. Under this symmetry the parity rule is broken by the static crystal field, allowing pure electric-dipole transitions. With $\mathrm{C}_{1}$ site symmetry the ground state becomes an A-type level, while the degeneracy of the excited state is removed giving two A-type levels. Just as for the vibrational levels we have to take into account that the unit cell contains four molecular units leading to correlation field splitting (also called Davydov splitting) of the electronic excited state energy levels. Under the $C_{2 h}$ cell symmetry the $8 \mathrm{~A}$ representation reduces to $2 \mathrm{~A}_{\mathrm{g}}+2 \mathrm{~B}_{\mathrm{g}}+2 \mathrm{~A}_{\mathrm{u}}+2 \mathrm{~B}_{\mathrm{u}}$. The crystal 


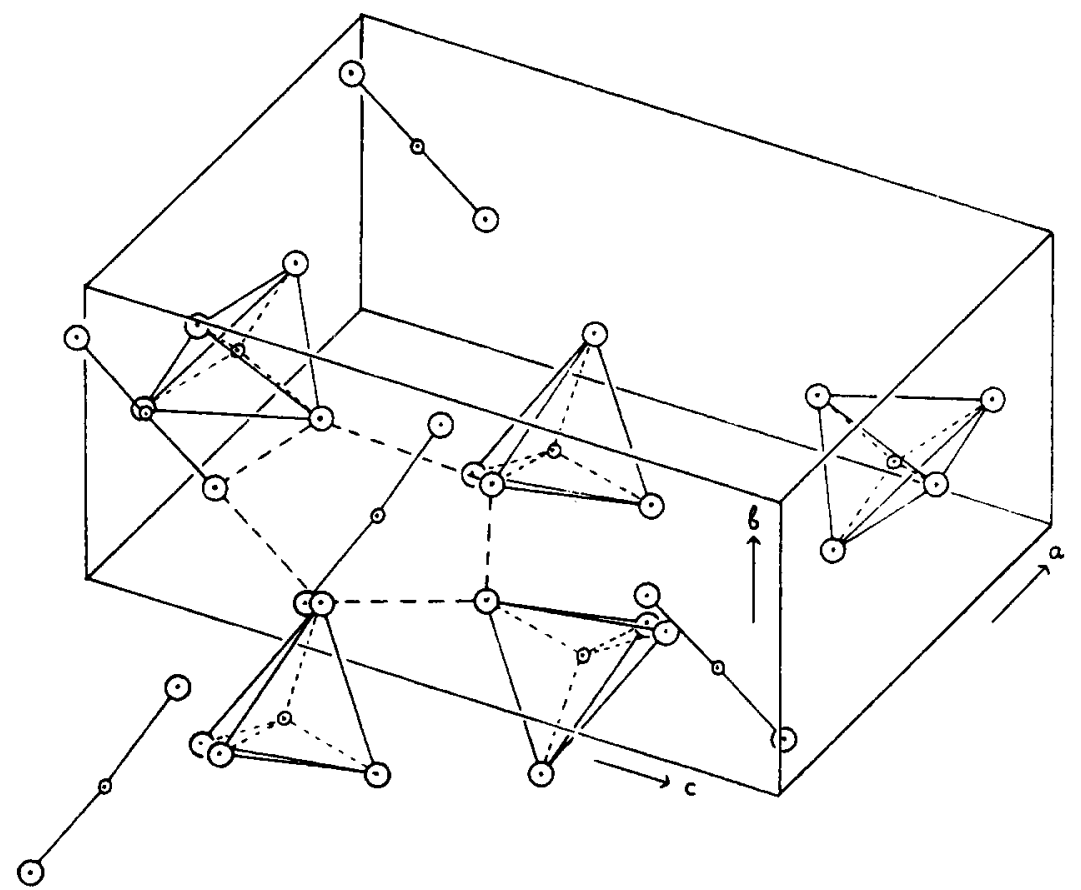

Fig. 2. Part of the crystal structure of $\mathrm{UO}_{2} \mathrm{MoO}_{4}$ showing the coordination of the uranium ion (distorted pentagonal bipyramid).

field splitting of the lowest excited level may be of the order of $10 \mathrm{~cm}^{-1}$, since the splitting in $\mathrm{Cs}_{2} \mathrm{UO}_{2} \mathrm{Br}_{4}$ was found to be $8-9 \mathrm{~cm}^{-1}[5,14,15]$. In view of the very short $\mathrm{U}-\mathrm{U}$ distance in $\mathrm{UO}_{2} \mathrm{MoO}_{4}$, viz., $4.195 \AA$, the additional correlation field splitting is expected to be of the same order of magnitude as the crystal field splitting.

Taking into account the $\mathrm{C}_{2 \mathrm{~h}}$ cell symmetry the only allowed pure electronic transitions from the $\mathrm{A}_{\mathrm{g}}$ ground state are to the ungerade components of the excited state levels. With the above arguments in mind the experimental shape of the intrinsic zero-phonon lines in the excitation and emission spectra can be easily interpreted (see fig. 3). The experimental line shapes (broken curves) are satisfactorily reproduced by a set of four Gaussians of which the parameters are given in table 3 . As can be seen from that table the standard deviation of the Gaussians is $3 \mathrm{~cm}^{-1}$, a reasonable value for the inhomogeneously broadened lines of a powder. The height of the component lines in the excitation spectrum may be considered as a measure of the relative transition probabilities. The shape of the total zero-phonon line in the emission spectra at different temperatures is now easily predicted by multiplying the height of the lines in 


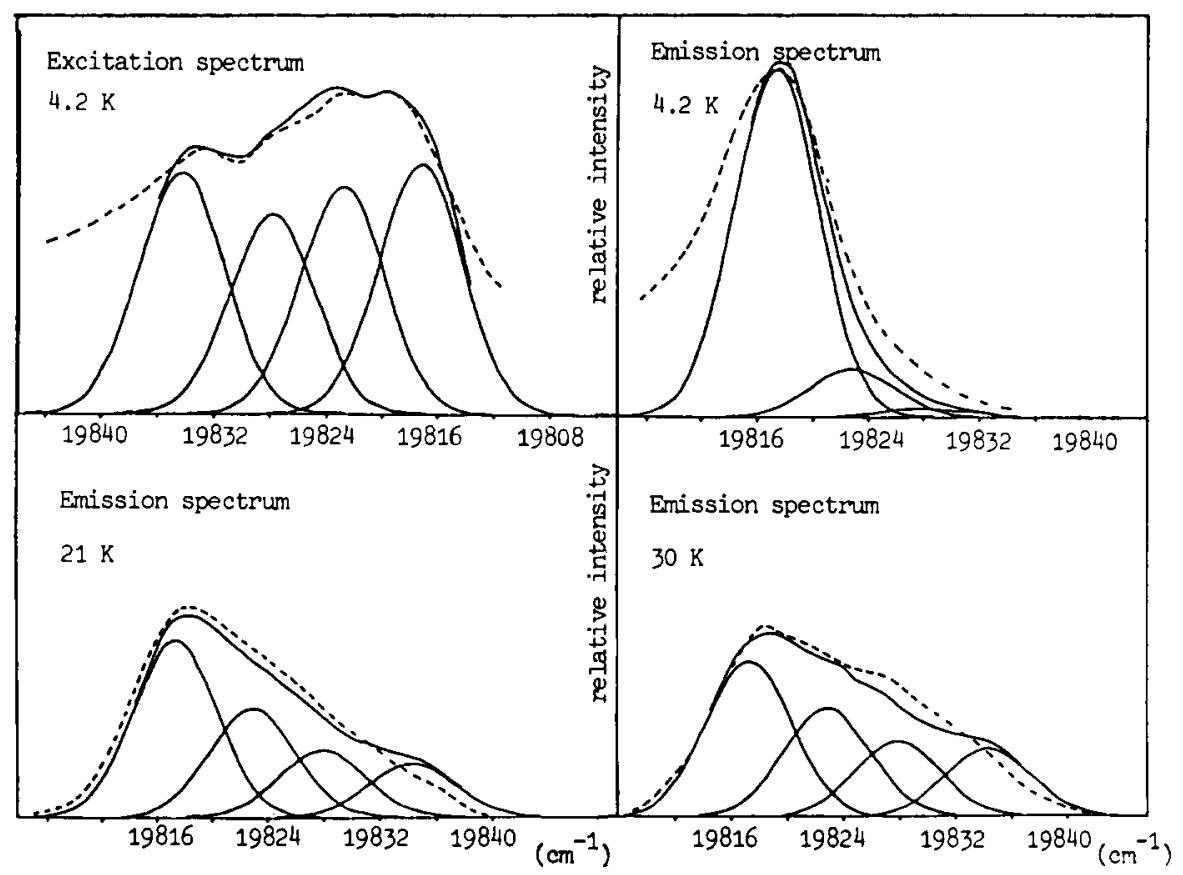

Fig. 3. Analysis of the zero-phonon line in the excitation and emission spectrum of $\mathrm{UO}_{2} \mathrm{MoO}_{4}$ at 4.2 K. The Gaussians represent the correlation field components which constitute the observed zero-phonon line (see text and table 3 for details). Broken line: observed curve; solid line: sum curve.

the excitation spectrum by the appropriate Boltzmann factor. The resulting heights at different temperatures are given in table 3 (the heights of the lines in the emission spectra are normalized to give the same total area under the sum curve for all temperatures). The positions of the Gaussians as given in table 3 correspond to the positions of the four ungerade correlation field components $\left(2 \mathrm{~A}_{\mathrm{u}}+2 \mathrm{~B}_{\mathrm{u}}\right)$ of the crystal field split $\Pi_{\mathrm{g}}$ excited level. These positions reveal that the crystal field and the correlation field splittings have indeed the expected order of magnitude.

It is of interest to observe that at very low temperatures $(1.2 \mathrm{~K})$ the maximum of the zero-phonon emission line shifts to $19812.0 \mathrm{~cm}^{-1}$, which may be interpreted as the position of the lowest $A_{g}$ component of the excited state. This also accounts for the low frequency deviation between the observed and predicted emission line at $4.2 \mathrm{~K}$. Clearly, at $4.2 \mathrm{~K}$ there is still some emission from the $\mathbf{A}_{\mathrm{g}}$ level. At higher temperatures this self-trapped emission will rapidly vanish due to thermal depopulation of the $\mathrm{A}_{\mathrm{g}}$ level. The population ratio of the two lowest excited state levels, viz., the $A_{\mathrm{g}}$ level at $19812.0 \mathrm{~cm}^{-1}$ and the lowest ungerade level at $19817.3 \mathrm{~cm}^{-1}$, is $1.7 \times 10^{-3}$ at $1.2 \mathrm{~K}, 0.16$ at 
Table 3

Parameter values of the Gauss functions used to fit the observed shape of the zero-phonon line in the excitation and emission spectra of $\mathrm{UO}_{2} \mathrm{MoO}_{4}$

\begin{tabular}{|c|c|c|c|c|c|}
\hline \multirow[b]{2}{*}{$\bar{y}$} & \multirow[b]{2}{*}{$\sigma$} & \multirow{2}{*}{$\frac{\text { Excitation }}{h(4.2 \mathrm{~K})}$} & \multicolumn{3}{|l|}{ Emission } \\
\hline & & & $h(4.2 \mathrm{~K})$ & $h(21 \mathrm{~K})$ & $h(30 \mathrm{~K})$ \\
\hline 19817.3 & 3 & 90 & 125.4 & 63.4 & 56.2 \\
\hline 19822.9 & 3 & 82 & 17.1 & 39.3 & 38.9 \\
\hline 19827.9 & 3 & 72 & 3.1 & 24.4 & 27.0 \\
\hline 19834.7 & 3 & 87 & 0.4 & 19.0 & 23.9 \\
\hline
\end{tabular}

$4.2 \mathrm{~K}$ and 0.70 at $21 \mathrm{~K}$. This indicates that the decay time for the emission from the $\mathrm{A}_{\mathrm{g}}$ level is considerably longer than for emission from the ungerade level. As mentioned above decay time measurements for emission from intrinsic and trap levels will be discussed in a subsequent paper.

Another deviation between the observed and predicted line shapes of fig. 3 appears at the high frequency side of the zero-phonon line in the excitation spectrum. Probably, vibronic coupling with small phonons results in a vibronic intensity contribution at the high frequency side of the line. Adopting a $20 \%$ lower value for the height of the Gaussian at $19834.7 \mathrm{~cm}^{-1}$ brings the predicted emission profiles completely in line with the observed shapes. The above analysis of the zero-phonon line shows that the vibronic lines are due to coupling with the $\mathrm{A}_{\mathrm{g}}$ correlation field components of the symmetric and asymmetric $\mathrm{UO}_{2}$ stretching modes. Obviously, also the vibronic lines consist of four correlation field components. However, the splittings are too small to be observed in the emission spectrum of the powder. Therefore only the observed maxima are given in table 1 . In principle, the maxima should be slightly temperature dependent. This effect, however, will be small and difficult to observe regarding the half width of the component lines and the limited wavelength accuracy of the measurements (about $\pm 1.5 \mathrm{~cm}^{-1}$ ). Nevertheless, a small temperature effect in the expected direction has indeed been observed.

The observed values for the vibrational quanta of the uranyl stretching modes in the electronic ground state as given in table 1 can be used to calculate the harmonic frequencies and anharmonicity constants of these modes. The relations between harmonic and observed frequencies are

$\nu_{01}=\left(1-2 x_{\mathrm{e}}\right) \omega_{\mathrm{e}}, \quad \nu_{12}=\left(1-4 x_{\mathrm{e}}\right) \omega_{\mathrm{e}}$

in which $\nu_{i j}$ denotes the observed transition frequency between the vibrational levels $i$ and $j, x_{\mathrm{e}}$ the anharmonicity constant and $\omega_{\mathrm{e}}$ the harmonic frequency. 
Using the vibrational frequency values observed in the Raman spectrum (see table 2) the following values are obtained: $\mathrm{A}_{\mathrm{g}}$ component of $\mathrm{UO}_{2}$ symmetric stretching mode, $\nu_{01}(\mathrm{ss})=745.1 \mathrm{~cm}^{-1}, \nu_{12}(\mathrm{ss})=743.0 \mathrm{~cm}^{-1}, \nu_{23}(\mathrm{ss})=740.9$ $\mathrm{cm}^{-1}, \omega_{\mathrm{e}}=747.2 \mathrm{~cm}^{-1}, x_{\mathrm{e}}=0.0014, \mathrm{~A}_{\mathrm{g}}$ component of $\mathrm{UO}_{2}$ asymmetric stretching mode, $\nu_{01}$ (as) $=884.5 \mathrm{~cm}^{-1}, \nu_{12}$ (as) $=876.5 \mathrm{~cm}^{-1}, \nu_{23}$ (as) $=868.5$ $\mathrm{cm}^{-1}, \omega_{\mathrm{e}}(\mathrm{as})=892.5 \mathrm{~cm}^{-1}, x_{\mathrm{e}}=0.0045$. The $x_{\mathrm{e}}$ value found for $\nu_{01}(\mathrm{ss})$ is in reasonable agreement with the corresponding value for $\mathrm{Cs}_{2} \mathrm{UO}_{2} \mathrm{Br}_{4}$ reported by Flint and Tanner [14].

\section{(B) Emission from defects}

The time averaged emission spectrum at $4.2 \mathrm{~K}$ is shown in fig. 4 . It looks quite different from the TRS emission spectrum of fig. 1. The intrinsic emission lines in fig. 4 are very weak, the spectrum being now dominated by a number of trap lines. The position of the main trap lines and their vibronic satellites are collected in table 4 . The parentage of the vibronic trap lines was determined by studying the emission spectra at several temperatures from 4.2 to $60 \mathrm{~K}$. The traps become thermally depopulated one after another at increasing temperature (see fig. 5). The deepest trap (t6 in table 4) disappears at about $40 \mathrm{~K}$.

The frequencies of the trap lines as given in table 4 are obtained from the laser excited emission spectra, since in the Xenon-lamp spectra all trap 0-0 lines are "split" due to self-absorption. In fig. 6 the zero-phonon region is

Table 4

Trapline positions in the emission spectrum of $\mathrm{UO}_{2} \mathrm{MoO}_{4}$ at $4.2 \mathrm{~K}$ (units: $\mathrm{cm}^{-1}$ )

\begin{tabular}{|c|c|c|c|c|c|c|c|}
\hline \multicolumn{2}{|c|}{ Trap position } & \multirow{2}{*}{$\begin{array}{l}\nu_{i j}{ }^{(4)} \\
-744\end{array}$} & \multicolumn{2}{|c|}{ Vibronic position ${ }^{(a)}$} & \multirow[t]{3}{*}{$\nu_{i j}^{(a)}$} & \multicolumn{2}{|c|}{ Vibronic position (a) } \\
\hline \multirow[t]{2}{*}{$\mathrm{tl}$} & 19775 & & v1 & 19031 & & & \\
\hline & & -883 & $\mathrm{v} 2$ & 18892 & & & \\
\hline \multirow[t]{3}{*}{$\mathrm{t} 2$} & 19722 & -741 & v1 & 18981 & -734 & v3 & 18247 \\
\hline & & -877 & $v 2$ & 18845 & -739 & $\mathrm{v} 4$ & 18106 \\
\hline & & & & & -873 & v5 & 17972 \\
\hline \multirow[t]{3}{*}{$\mathrm{t} 3$} & 19710 & -739 & $\mathrm{v} 1$ & 18971 & -734 & v3 & 18237 \\
\hline & & -875 & $v 2$ & 18835 & -739 & $v 4$ & 18096 \\
\hline & & & & & -873 & v5 & 17962 \\
\hline \multirow[t]{3}{*}{14} & 19676 & -742 & $\mathrm{vl}$ & 18934 & -736 & v3 & 18198 \\
\hline & & -876 & $\mathrm{v} 2$ & 18800 & $(-745)$ & $\mathrm{v} 4$ & (18055) \\
\hline & & & & & -873 & $v 5$ & 17927 \\
\hline \multirow[t]{3}{*}{ t5 } & 19635 & -735 & v1 & 18900 & -731 & v3 & 18169 \\
\hline & & -882 & $v 2$ & 18753 & -733 & $\mathrm{v} 4$ & 18020 \\
\hline & & & & & -881 & v5 & 17872 \\
\hline \multirow[t]{3}{*}{ t6 } & 19548 & -733 & v1 & 18815 & -730 & v3 & 18085 \\
\hline & & -871 & $\mathrm{v} 2$ & 18677 & -731 & v4 & 17946 \\
\hline & & & & & -870 & v5 & 17807 \\
\hline
\end{tabular}

(a) See table 1 for meaning of $\nu_{i j}$ and $v j$. 


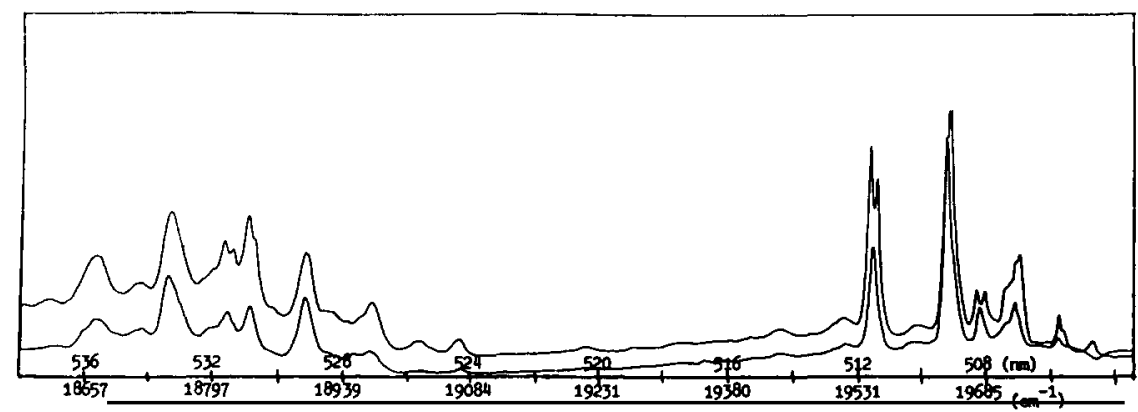

Fig. 4. Part of the steady-state emission spectrum of $\mathrm{UO}_{2} \mathrm{MoO}_{4}$ at $4.2 \mathrm{~K}$. Upper trace: Xenon-lamp excitation; $\lambda_{\text {exc }}: 430-490 \mathrm{~nm}$; lower trace: laser excitation; $\lambda_{\text {exc }}: 483 \mathrm{~nm}$.

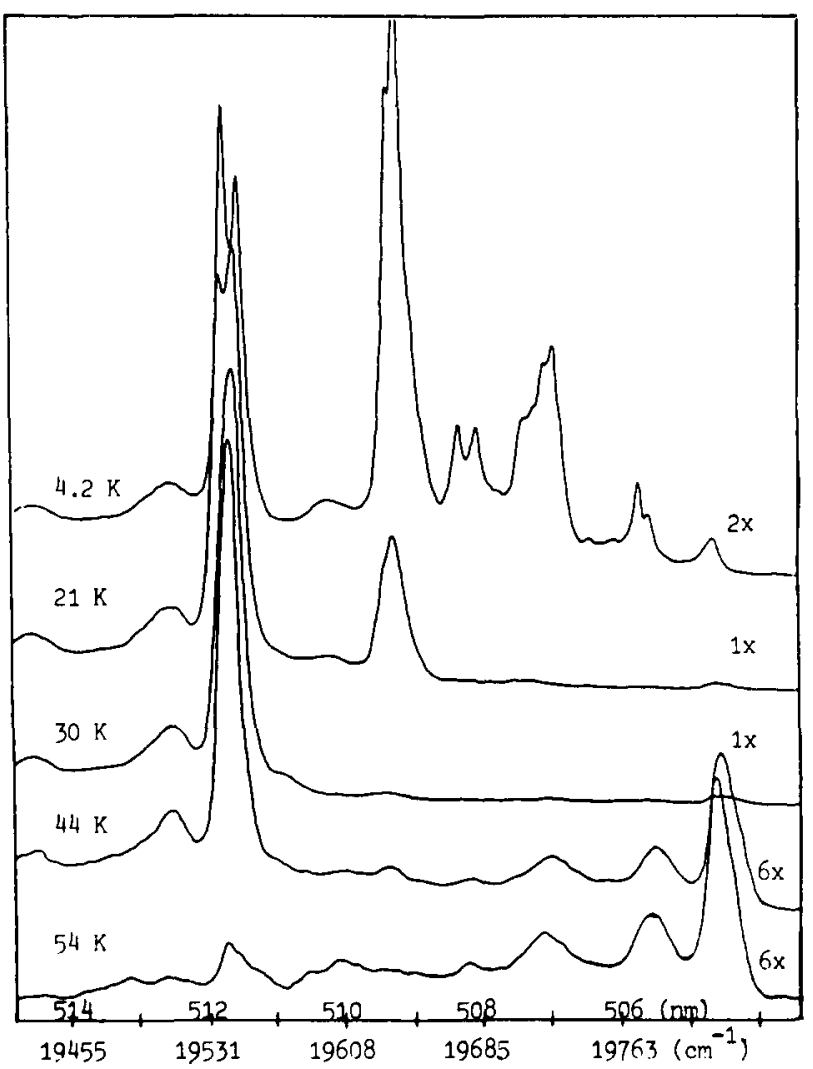

Fig. 5. Zero-phonon part of the steady-state emission spectrum of $\mathrm{UO}_{2} \mathrm{MoO}_{4}$ at several temperatures. Note the change in intensity scale as indicated by the multiplication factors. Xenon-lamp excitation, $\lambda_{\text {exc }}: 430-490 \mathrm{~nm}$. 


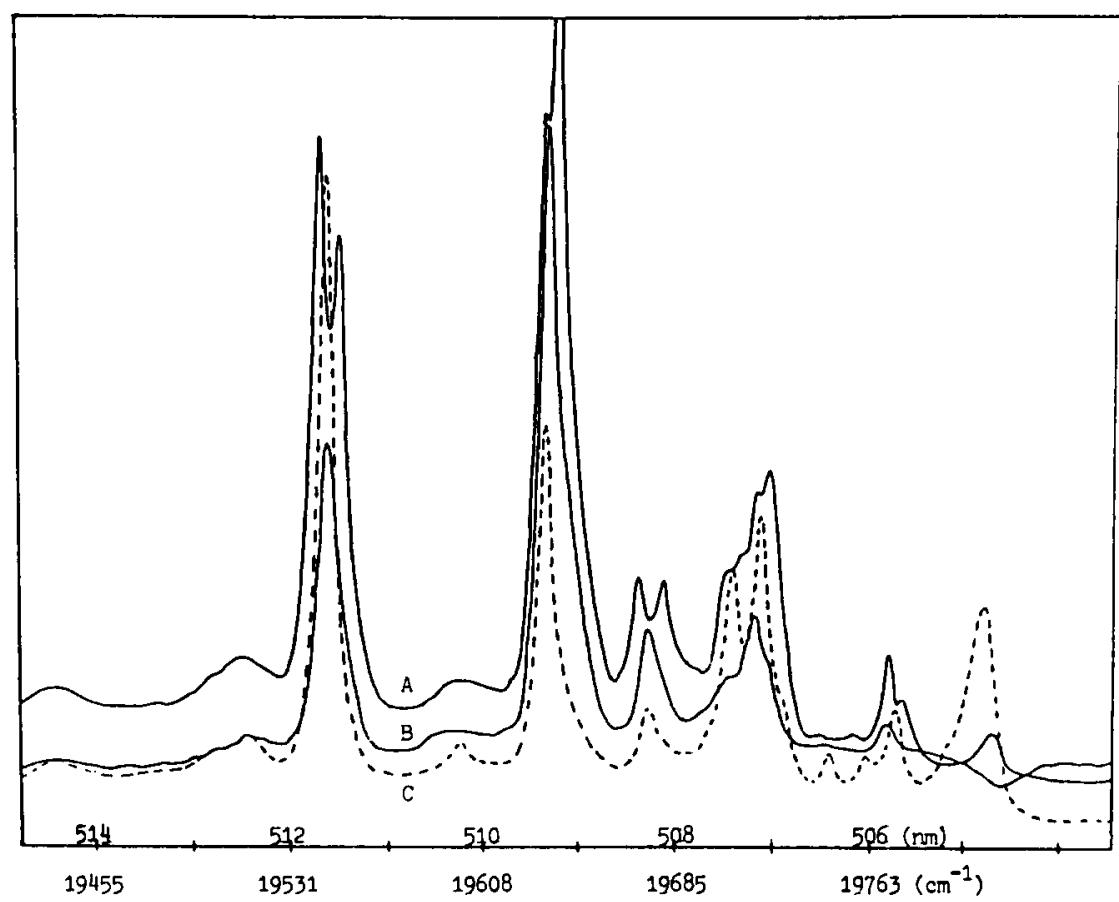

Fig. 6. Zero-phonon part of the steady-state emission spectrum of $\mathrm{UO}_{2} \mathrm{MoO}_{4}$. A: Xenon-lamp excitation at $4.2 \mathrm{~K} ; \lambda_{\text {exc }}: 430-490 \mathrm{~nm}$; B: laser excitation at $4.2 \mathrm{~K} ; \lambda_{\text {exc }}: 483 \mathrm{~nm}$; C: Xenon-lamp excitation at $1.2 \mathrm{~K} ; \lambda_{\text {exc }}: 430-490 \mathrm{~nm}$.

shown, obtained with laser excitation at $4.2 \mathrm{~K}$ and with Xenon-lamp excitation at 4.2 and $1.2 \mathrm{~K}$. The observed differences may be explained as follows: Laser excitation took place in a strong intrinsic absorption line at $483 \mathrm{~nm}$, mainly leading to direct excitation of intrinsic centres in the surface layer of the microcrystallites of the powder. By migration of intrinsic excitons the traps become excited. At low temperature the traps return to the ground state by a spontaneous emission process. This emission occurs mainly in the surface layer so that no self-absorption can take place. The emission spectra obtained with the Xenon-lamp are the result of a broad-band excitation (interference filter with a maximum at $460 \mathrm{~nm}$ and a half-width of $60 \mathrm{~nm}$ ). At $4.2 \mathrm{~K}$ this results in direct excitation of both intrinsic and trap sites, whereby a substantial amount of exciting photons penetrates deeper in the crystallites than occurs with laser excitation, since their wavelength corresponds to lower absorption coefficients. Migration of intrinsic excitons populates the excited trap levels. The subsequent emission from the trap sites emerges not only from the surface layer but also from the bulk of the crystallites, leading to "split" peaks due to self-absorption. At $1.2 \mathrm{~K}$ the same direct excitations occur. However, migration of 
intrinsic excitons is much slower now as indicated by the increase of intrinsic emission (from the $A_{g}$ level at $19812.0 \mathrm{~cm}^{-1}$, see fig. 6). This reveals that excitons in the $\mathrm{A}_{\mathrm{g}}$ excited levels might have a considerably lower migration probability than from the higher correlation field levels. Therefore, trap emission occurs mainly from the surface layer where the higher trap concentration will be found and no self-absorption takes place.

It is immediately clear from table 4 that all observed trap centres are distorted uranium sites. The exact nature of the different trap sites is not easily determined. The intrinsic uranyl groups have already low symmetry and, therefore, appreciable changes in selection rules may not be expected. The observation that the trap zero-phonon lines are stronger than their vibronic satellites in contrast with the emission from intrinsic centres merely results from the fact that the intrinsic zero-phonon line is seriously weakened by self-absorption. In the laser excited emission spectrum of fig. 4 strong selfabsorption even results in a dip in the background at the position of the intrinsic zero-phonon line. Finally, we remark that the intensity of the intrinsic emission increases when the temperature is raised from 4.2 to $50 \mathrm{~K}$, showing that in this temperature range the loss in emission intensity due to temperature quenching at killer sites is smaller than the gain in intrinsic emission due to depopulation of the trap sites.

\section{References}

[1] J.Th.W. de Hair and G. Blasse, J. Lumin. 14 (1976) 307.

[2] J.Th.W. de Hair and G. Blasse, J. Solid State Chem. 19 (1976) 263.

[3] G. Blasse, J. Electrochem. Soc. 124 (1977) 1280.

[4] G. Blasse, K.C. Bleijenberg and D.M. Krol, J. Lumin. 18/19 (1979) 57.

[5] D.M. Krol and A. Roos, Phys. Rev. B 23 (1981) 2135.

[6] D.M. Krol, Chem. Phys. Lett. 74 (1980) 515.

[7] D. Hall, A.D. Rae and T.N. Waters, Acta Cryst. 20 (1966) 160

[8] Yu. N. Mikhailov, V.G. Kuznetsov and E.S. Kovaleva, Zh. Strukt. Khim. 6 (1965) 752.

[9] Yu.N. Mikhailov and V.G. Kuznetsov, Russ. J. Inorg. Chem. (Engl. Transl.) 16 (1971) 1340.

[10] V.N. Serezhkin, L.M. Kovba and V.K. Trunov, Sov. Phys. Crystallogr. 17 (1973) 999.

[11] V.N. Serezhkin, V.K. Trunov and L.G. Makarevich, Sov. Phys. Crystallogr. 25 (1980) 492.

[12] L.M. Kovba, V.K. Trunov and A.I. Grigor'ev, Zh. Strukt. Khim. 6 (1965) 919.

[13] D.P. Wong, A.Y.C. Wong and E.Y. Wong, J. Chem. Phys. 56 (1972) 2838

[14] C.D. Flint and P.A. Tanner, Inorg. Chem. 20 (1981) 4405.

[15] C.D. Flint and P.A. Tanner, J.C.S. Faraday II, 75 (1979) 1168.

[16] R.G. Denning, T.R. Snellgrove and D.R. Woodwark, Mol. Phys. 32 (1976) 419.

[17] R.G. Denning, T.R. Snellgrove and D.R. Woodwark, Mol. Phys. 37 (1979) 1109. 